\title{
A Green GIS Solution against Air Pollution in the Province of Bergamo: The Paulownia Tree
}

\author{
Barbara Marana \\ Department of Engineering and Applied Science, University of Bergamo, Bergamo, Italy \\ Email: barbara.marana@unibg.it
}

How to cite this paper: Marana, B. (2018) A Green GIS Solution against Air Pollution in the Province of Bergamo: The Paulownia Tree. Journal of Geographic Information System, 10, 193-218. https://doi.org/10.4236/jgis.2018.102010

Received: February 6, 2018

Accepted: April 7, 2018

Published: April 10, 2018

Copyright $\odot 2018$ by author and Scientific Research Publishing Inc. This work is licensed under the Creative Commons Attribution-NonCommercial International License (CC BY-NC 4.0). http://creativecommons.org/licenses/by-nc/4.0/

\section{(c) (i) (8) Open Access}

\begin{abstract}
The paper describes a GIS approach to identify the most suitable areas for growing the Paulownia tree in the Province of Bergamo; this work will become the subject of a dissertation thesis at the School of Engineering of the University of Bergamo. Paulownia is quite an ancient tree, well known especially in the far east countries, for its wonderful flowers and the quality of the wood which is a source of certain profit. The paper is focused on the employment of the Paulownia tree against air pollution, since its big leaves absorb high amounts of $\mathrm{CO}_{2}$ in the atmosphere and can capture the small particles of pollutants in the air ten times more than any other tree species. First, the analysis identifies the most favourable areas for its growth in the Province of Bergamo. Secondly, among the latter, the analysis detects the strategic areas for its growth near the most polluted zones. Finally, a quantitative evaluation is carried out about the trees contribution against pollutants in the atmosphere.
\end{abstract}

\section{Keywords}

Air Pollution, Province of Bergamo, Paulownia Tree, Selection of the Best Growth Areas, Analysis of the Most Polluted Areas, Quantitative Contribution of the Tree against Air Pollution

\section{Introduction}

The problem of air pollution is of great interest nowadays, since many kinds of dangerous emissions flow directly in the air we breathe. The consequences are of great danger for human and animal health and the number of ill and dead people is increasing also with a lack of the needed control, information and intervention by the authorities. Of course also the environment and cultural heritage are endangered by this phenomenon. 
The cause is mostly anthropic and so we are directly responsible for what is happening in many places in the world.

For this reason, the idea developed in this study has been to identify a possible green solution that could help to improve the current situation. The suggestion of the Paulownia tree has come from one student of the GIS course at the University of Bergamo, School of Engineering. The proposal shows that young people are deeply concerned about environmental issues and they are worried for their future. This is important, since a conscious approach is needed and information has to be spread.

The area selected for the analysis is the Province of Bergamo, since in our University the students mostly live in the town of Bergamo and the surrounding valleys, and also because air pollution is a crucial issue also here, due to human action and particular terrain morphology and climate conditions. The first step has been to identify other studies suggesting the use of this tree against pollution, but the only found reference is that of a Russian company, called "Environmental Investment" [1] [2], which cultivates these trees for commercial investment, but it also takes into account the ecologic side, by suggesting that highly polluting companies should plant these fast-growing trees on the territory of their factories for quick and effective compensation of environmental impacts [1]. So, it has been decided to start a new approach suggesting the employment of this specific tree against pollution as an example to be followed by many.

\section{The Paulownia Tree}

Paulownia, also known as empress or kiri tree, has its origins in central and western China. Historical records indicate that it was highly prized for its medicinal, ornamental, and timber uses [3] [4]. It is characterised by wonderful purple scented flowers (Figure 1) and very big leaves which reach the size of 60 $\mathrm{cm}$ and more (Figure 2).

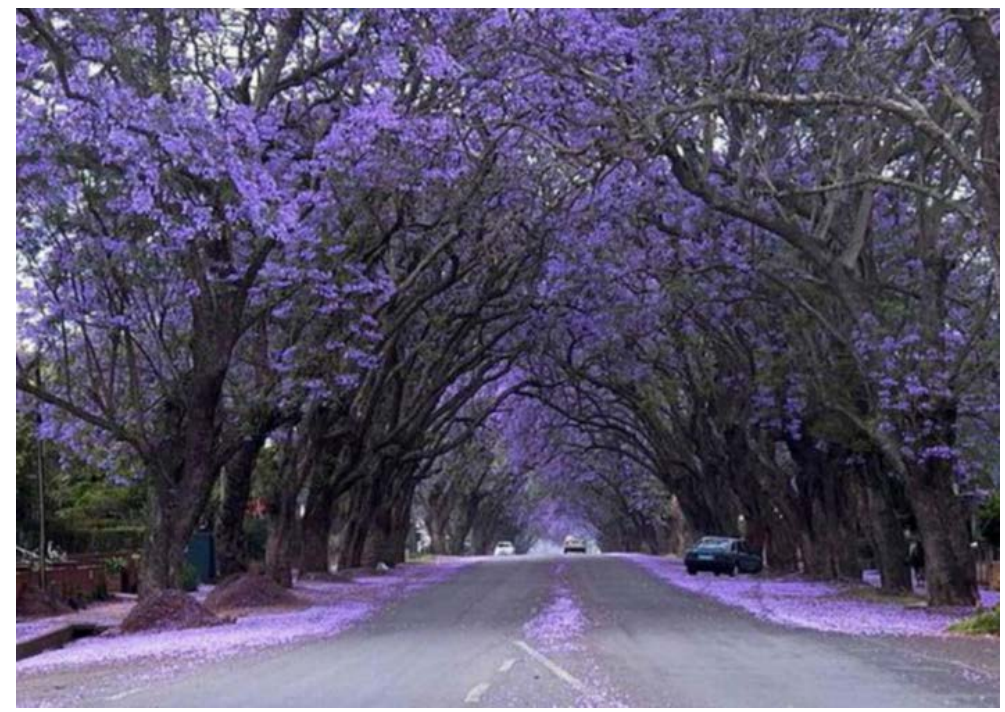

Figure 1. A street hedged with wonderful Paulownia trees [7]. 


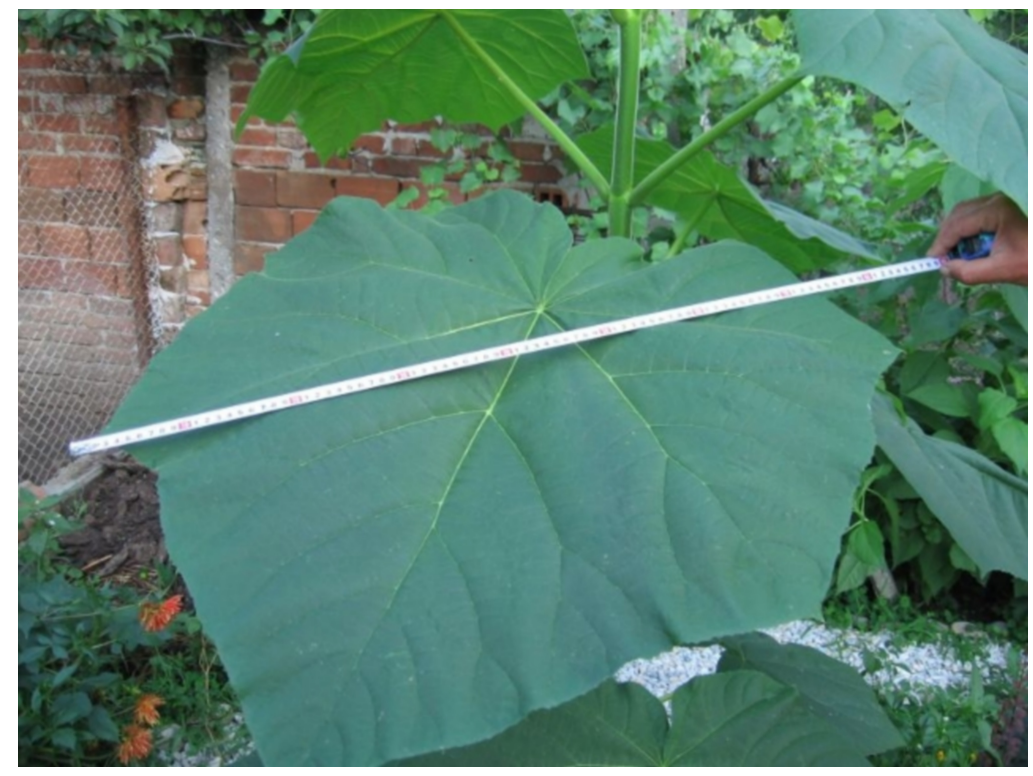

Figure 2. The big Paulownia leaves [8].

The Paulownia tree existed in North America prior to the last ice age [5]. The seeds of the tree were not introduced to the West until 1834 and it did not take long for the empress tree to spread [4].

The genus was named Paulownia after Princess Anna Pavlovna of Russia, daughter of Tsar Paul I of Russia [3]. By tradition in Japan, when a girl child is born, a Paulownia tree is planted for her and, when she gets married, her wedding chest is built from the tree. Japanese people also believe that the tree should be planted next to the house so that the Phoenix would come to protect them and bring good luck [6].

The Paulownia tree originally grew only in mild climates. In time, some laboratory researches have allowed to artificially select new species of Paulownia which can adapt to cold winters and dry summers. The tree can now grow in places with higher temperatures and also at higher latitudes, which means colder regions. It is important to underline, as it will be explained later, that air pollution is responsible of the rising of the air temperature of our planet. Other genetic modifications allowed to obtain a better, fast growing, light and highly-prized timber which is much appreciated for commercial purposes and business plans.

Because of its fast spreading, in some US states [9] Paulownia is classified as an invasive plant, due to the huge quantities of seeds produced and rapid growing. It may become invasive, but it is still classified as not invasive in Europe and in other countries in the world [9], even if it must be contained so as to prevent the problem.

However, many laboratory studies and manipulations have provided species of cloned Paulownia which produce sterile seeds, this way bypassing the problem [10].

Anyway, the tree, with the purpose of a remunerative harvesting plan, is spreading in the world, because of the fast growing, high prized timber which 
allows to achieve high profits in a relatively short time [11]-[16]. It is also known that the former US President Jimmy Carter grows about 15 acres of Paulownia trees in his farm in Georgia [17] [18] [19] [20].

\subsection{Benefits and Use of Paulownia Trees}

Many benefits and uses can be derived from the Paulownia trees and they are described hereafter [8] [21] [22] [23].

Ornamental Use-The tree has wonderful purple scented flowers and big leaves which provide shade.

Forestry-The wood is fast growing and fire resistant (University of Texas states it is fire-resistant up to a flashpoint of $477^{\circ}$ ) [23]. For this reason, Paulownia trees could be planted in areas devastated by fire.

Soil environmental issues-Paulownia is capable of adapting, growing and developing in poor soils, this way improving and recovering them [21]. The huge leaves of Paulownia, which reach over $60 \mathrm{~cm}$ in diameter, after falling to the ground, fertilize the soil with their high nitrogen levels. The tree can help in case of soils polluted with heavy metals and harmful substances, by absorbing them. It is also useful for waste water and erosion control: the big roots grow and expand rapidly, allowing to absorb polluted water and to consolidate the soil. It can be used also as windbreak.

Air Pollution-Paulownia helps to clean the air polluted by harmful gases and particles, which reach high concentrations, especially in large industrial cities. Paulownia can absorb 10 times more $\mathrm{CO}_{2}$, necessary for its metabolism, than any other tree species, releasing large quantities of $\mathrm{O}_{2}$ through photosynthesis [21].

Each acre of trees can absorb 13 tons of harmful $\mathrm{CO}_{2}$ gases and particles from the air each year and each tree can release about $13 \mathrm{lbs}$ of oxygen per day [23]. All this is made possible by the big leaves of the Paulownia tree that, for this reason, can be described as the "green lung" of our cities [8]. The wood can also be used to produce biomass, for fuel and for heating, which shows an interesting ecological property, since it emits the lowest amounts of harmful substances if compared to other materials used in the power industry [21].

Medicine-The pharmaceutical industry produces medicines based on Paulownia with a good action for the liver, kidneys and lung diseases [8].

Commerce-The wood is very light, it does not warp, crack or twist. It is used for furniture, musical instruments, doors, mouldings, window frames, poles, pulp, paper, veneer, plywood, cladding. It is a worthy investment since the tree can be harvested in five to seven years and then it regenerates from the stumps.

Food-Honey can be produced from the flowers (most of the honey from China comes from the Paulownia tree), tea from the leaves and the flowers can be eaten. The tree is, as just said, a melliferous plant [24], so it can favour the spreading of bees, which are nowadays highly endangered by human activities.

Fodder-The big leaves, with high values of proteins, can be used as food for animals. 
According to the interesting properties of Paulownia just described against pollution, a thorough search has been made so as to identify other studies which suggested the use of this tree for improving the air quality by many of the dangerous emissions which pollute the atmosphere. The only case we found is related to a Russian company, called "Environmental Investment" [1] [2]. The company has set up a biotech nursery for cultivating seedlings of this fast-growing tree to be sold to different customers and for different purposes. Here both the economic investment and the ecologic side are taken into account. This is well demonstrated by the words of the CEO of "Environmental Investment" Svetlana Nikulenkova: "We recommend that large companies-pollutants plant the fast-growing trees on the territory of their factories, establishing parks and squares, creating recreation areas, to plant the trees along the roads and highways for quick and effective compensation of environmental impacts" [1]. Nothing more has been found about the employment of this specific tree against pollution. The paper hence starts a new research path, also with the hope that it might become an example and suggestion for many others in the world. Of course in Italy there are other species of trees which can absorb $\mathrm{CO}_{2}$ and Ibimet [25], i.e. the Institute of Biometeorology of the CNR (National Research Council) in Bologna, has started a thorough research in the employment of trees in the cities and has identified some interesting "anti-pollution" local plants, such as the linden, hawthorn and ash trees [26]. The choice of the Paulownia, instead of local trees, in this study, is based on its interesting properties, previously described, against air pollution, since Paulownia can absorb 10 times more $\mathrm{CO}_{2}$, necessary for its metabolism, than any other tree species, releasing large quantities of $\mathrm{O}_{2}$ through photosynthesis [21].

\subsection{Climatic and Soil Conditions for Growing Paulownia}

The ideal climatic and soil conditions for growing Paulownia are listed hereafter [27] [28].

Temperature-For the new selected varieties of Paulownia, the suggested range is between $-24^{\circ} \mathrm{C}$ and $45^{\circ} \mathrm{C}$. The original ones adopted only to milder climates, as previously said.

Rainfalls-Soil and air humidity are very important for growing Paulownia. The suggested yearly average rainfalls should be above $800 \mathrm{~mm}$. Insufficient watering slows the growth but does not kill the plant. For optimal growth, during the first months of growth, it is crucially important to water each plant with 20 litres per week.

Wind-Paulownia needs to be planted in areas where winds are not stronger than $28 \mathrm{~km} / \mathrm{h}$, since wind is dangerous for young plants.

Altitude-The ideal height is about $700-800 \mathrm{~m}$, especially to be easily reached by vehicles, but Paulownia well adapts up to $2000 \mathrm{~m}$.

Aspect-The best aspects are South, South-West and South-East, i.e. the areas with more solar exposure. 
Soil $\mathrm{PH}-$ The soil $\mathrm{PH}$ should range between 5 and 8.9. In this analysis the range has been selected between 5.5 and 8 , as suggested by other more stringent requirements [6] [29].

Soil texture-Paulownia is a highly adaptive species and grows well on many types of soils. However, the most appropriate and recommended soils are light, well drained and sandy soils with or without slopes. Clay and soaked soils must be avoided. Soils with more than $25 \%$ of clay and porosity under $50 \%$ are not recommended.

Soil Depth-Young Paulownia plants grow well when the soil depth is at least 1.5 - 2 meters.

Soil Salinity-Paulownia does not tolerate salinity over $1 \%$.

Soil OC quantity-Soil carbon is present in two forms, inorganic an organic. Organic Carbon, indicated with OC, represents about $60 \%$ of the organic substance in soils and it has a positive influence on many soil properties and it can be found in its first decimetres. It allows the aggregation and stability of soil particles and improves the soil fertility by incrementing the microbic activity and the availability of nutritive elements such as azote and sulphur. The minimum level of OC for an acceptable soil is 1\% [30] [31].

\section{Air Pollution}

Air pollution is defined as the "presence in the air of some substances at such levels to cause negative effects on men and animal health, environment and cultural heritage" [32]. The air we breathe is highly precious and it should be a common purpose to make it better. This is an important issue and many events happening in the world are cause of worry, such as the rising of the Earth temperature, the melting of glaciers, diseases, etc. There is also some good news, like the new green project which is going to be realized in China in a short time: Liuzhou Forest City [33] [34] (Figure 3) will be built in the north of Liuzhou, in the mountain area of Guangxi, in the southern part of China. China, with its

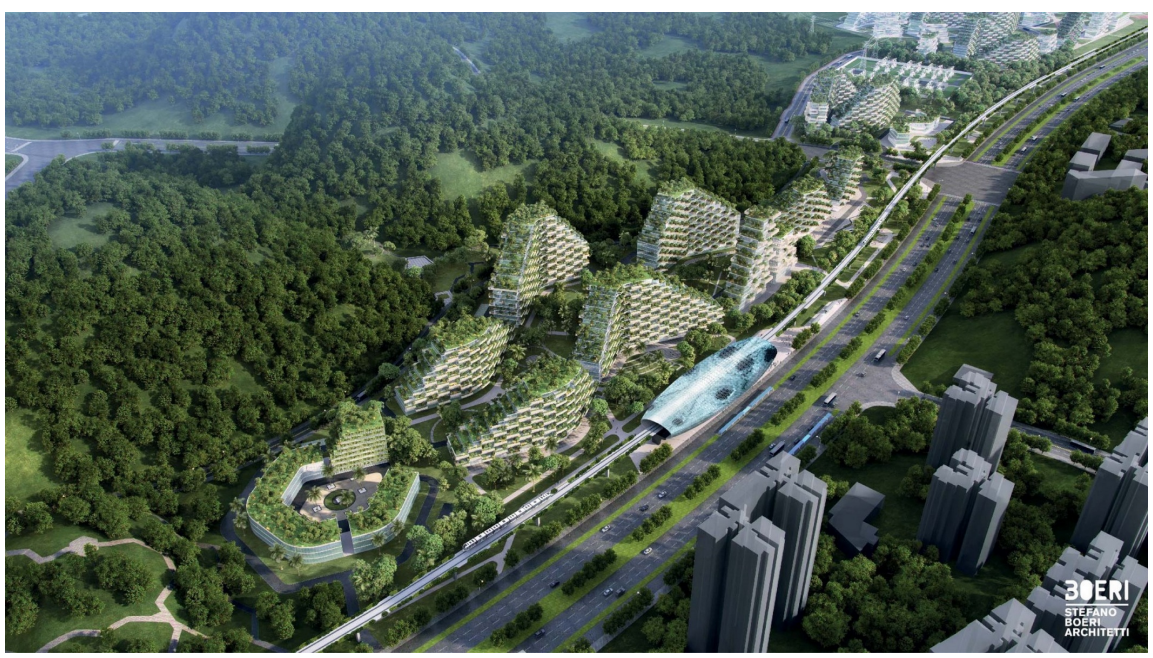

Figure 3. Liuzhou forest city by Stefano Boeri [36]. 
huge metropolises, is a country with the highest rates of air pollution, but recent policies are oriented toward green solutions; in fact, this new project is commissioned by Liuzhou Urban Planning Municipality. The Italian architect Stefano Boeri [35] has planned a scheme for a green vertical city solution and it is under construction in an area that covers 175 hectares along the Liujiang river. In total, the City will host 40,000 trees and almost 1 million plants from over 100 species. It will provide homes for 30,000 people, across a variety of residential areas, and also commercial and recreational spaces, two schools and a hospital. It will be connected to Liuzhou through a fast rail line serviced by electric trains. Mr. Boeri estimates that the greenery, diffused not only in the parks and gardens or along the streets, but also over building facades, will absorb nearly 10,000 tonnes of $\mathrm{CO}_{2}$ and 57 tonnes of pollutants per year, while also producing approximately 900 tonnes of oxygen. It will also contribute to decrease the average air temperature, and to create noise barriers [36] [37].

\section{Air Pollution in the Province of Bergamo}

The territory taken into account in this paper is the Province of Bergamo [38] (Figure 4), which covers an area of about $2750 \mathrm{~km}^{2}$, located mostly in the central part of the Lombardy mountainous region, with Alps and hills, and in a little part of the Lombardy Plain. Its morphology (Figure 5) well reflects this heterogeneity, since it is $64 \%$ mountains, $12 \%$ hills and $24 \%$ plane.

In a wide part of the Lombardy region and in the whole Padana Plain, like other Italian and European regions, the air quality is poor; it is certainly better than in the past years, since some dangerous pollutants have nearly disappeared, but others are now reaching high levels, such as particulate matters (PM10 and PM2.5), azote oxides $\left(\mathrm{NO}_{2}\right)$ and ozone $\left(\mathrm{O}_{3}\right)$.The causes can be found in the high level of urbanization and industrialization of the territory. Also the geographical and climatological conditions are not favourable, being the Padana Plain surrounded by mountains and characterized by light wind and high atmospheric stability. The situation is also aggravated by our planet climate change which, in

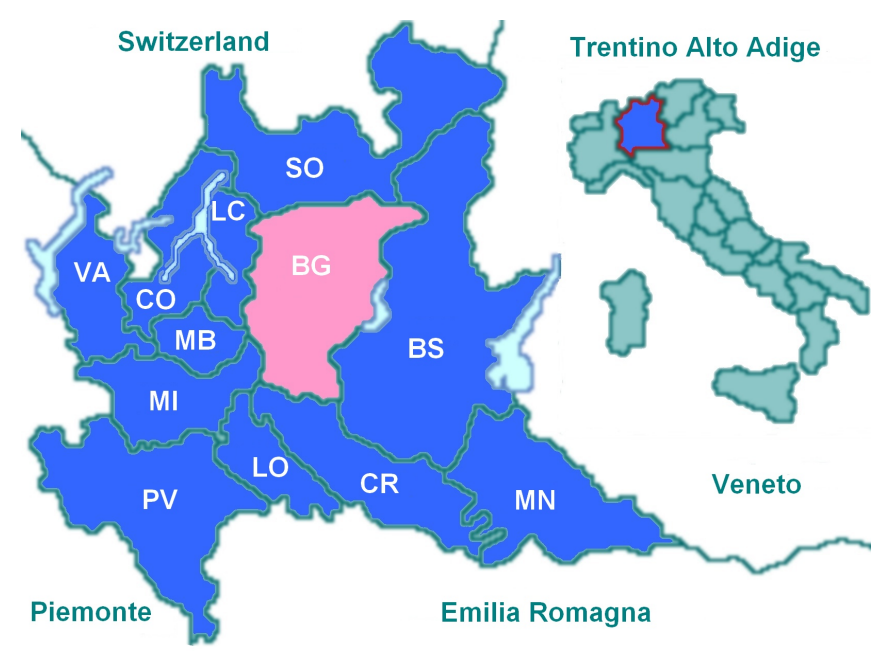

Figure 4. The Province of Bergamo in northern Italy [39]. 


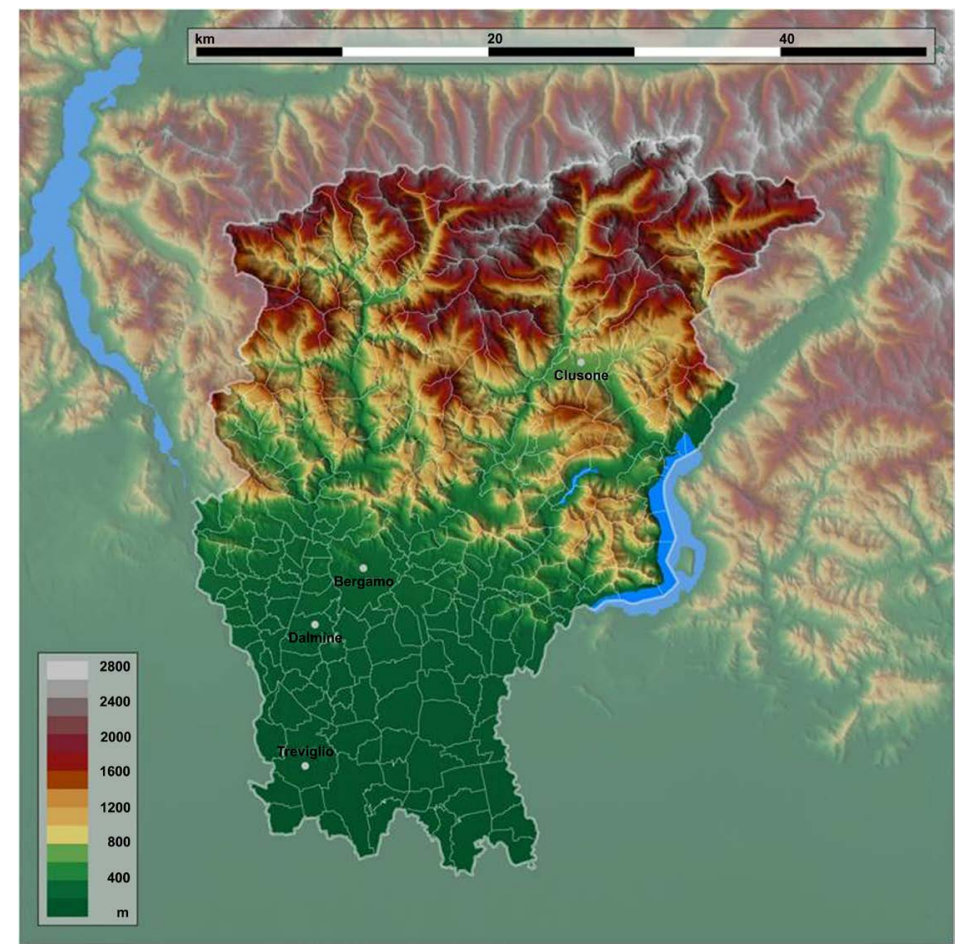

Figure 5. The Province of Bergamo morphology [40].

the Lombardy Region, causes less winter rainy days, which can clean the atmosphere mostly from the particulate PM10 and PM2.5, and provides more summer sunny days, this way improving the formation of all the pollutants favoured by the solar radiation [32]. The Province of Bergamo is concerned about the high levels of air pollutants reached in recent years and it has started a policy toward green solutions. In the town of Bergamo nearly 8000 trees of different species can be found and, recently, 700 more have been planted along the streets [41]. According to Istat (National Institute of Statistics), Bergamo has an availability of urban green of $17.4 \mathrm{~m}^{2}$ per capita. This is a relatively low endowment, but in recent years much has been done to improve the situation: in 2011 for each citizen there were $15.2 \mathrm{~m}^{2}$ of green, while in 2014 they had raised to $18.4 \mathrm{~m}^{2}$. The intention is to work and make Bergamo a greener city [42]. The analysis developed in this paper, about air pollutants in the Province of Bergamo, is described below.

\section{The Project}

The work developed so far has aimed at identifying the best places to grow the Paulownia tree in the Province of Bergamo, according to the criteria described above.

They are as follows:

Elevation-not above $800 \mathrm{~m}$; actually, Paulownia can adapt well up to 2000 $\mathrm{m}$, but it has been decided to set this lower threshold because the plantations would be easier to reach and, most of all, since the aim of the research is to find the best fitting areas to grow these trees so as to fight air pollution and, as it is 
well known, pollution reaches the highest values in the plain and hills, but not so much at higher altitudes, i.e. the mountain regions.

Aspect-South, South East and South West areas.

Rainfalls-more than $800 \mathrm{~mm}$ per year. The results will prove that the minimum quantity is by far exceeded for the Province of Bergamo and for this reason this layer will not be considered for the final analysis.

Temperature-since the suggested range is between $-24^{\circ} \mathrm{C}$ and $45^{\circ} \mathrm{C}$ and in the Province of Bergamo the temperature never exceeds this value, this factor has not been taken into account.

Wind speed-not over $28 \mathrm{~km} / \mathrm{h}$. For this reason, the wind map has been developed for the Province of Bergamo, as it will be later explained, but the results will confirm that wind is not an issue in the selected area.

Soil texture-loam, sandy loam and silt loam soils are suggested. Besides the soil texture requirement, also the soaked soils must be avoided and for this reason also a new layer has been derived by applying the union tool, in ArcMap, to the shapefiles: areas at high vulnerability for water resources, flood and outflow prone areas and the PAI (Plan for hydrogeological asset of the Po basin) layers (A, B and C brackets) which show the borders of the Po river and its main tributaries. In this case, only the $\mathrm{C}$ bracket has been used, since it outlines a wider area, around the $\mathrm{A}$ and $\mathrm{B}$ ones, prone to flooding.

Soil PH-between 5.6 and 7.9.

Soil depth-more than $1.5 \mathrm{~m}$.

OC quantity-minimum $1 \%$.

Salinity - the tree needs soils with salinity non above $1 \%$; for this reason, the information about salinity in the Lombardy region has been derived from the ERSAF (Regional Agency for the Services to Agriculture and Forests) website [43] as a pdf document [44]. As it is shown in Figure 6 and explained by

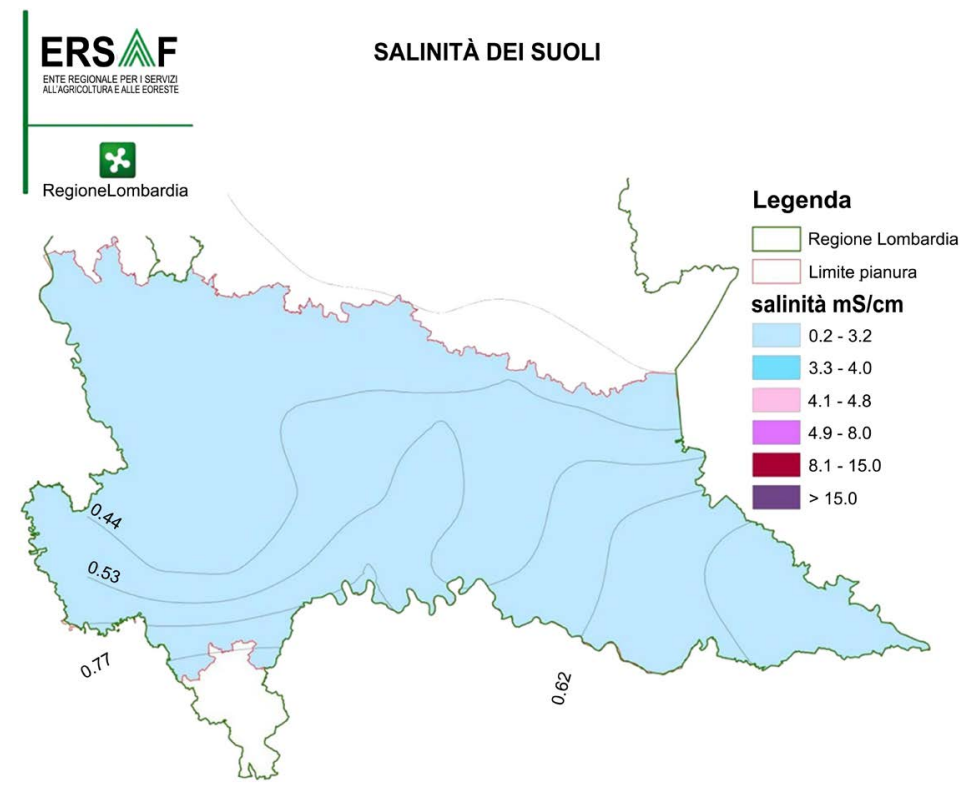

Figure 6. The salinity map of the Lombardy region by ERSAF [44]. 
ERSAF, in the Lombardy region there are no saline soils nor zones prone to salinization risk. The level of salinity in the map is measured in $\mathrm{mS} / \mathrm{cm}$, which is the electric conductivity in millisiemens per centimetre, and not in \%, but the figure well shows what just said and, for this reason, salinity has not been taken into account, since in this region this is not a problem.

Land Use-It has also been decided to take into account the DUSAF (Agriculture and Forest Soil Destination of Use) 4.0 land use shapefile, so as to focus the search only in areas with specific land use requisites that will be described later.

The two following listed subjects have been analysed, as possible criteria to identify the best fitting areas, but then have been discarded for the reasons explained:

Slope - the tree grows independent of the terrain slope.

Geology - at first it had been thought to discard calcareous terrains, by selecting them in the shapefile Geology of the Province of Bergamo, since it is known that usually many trees do not usually grow well here for the poorness of nutrients in the soil, but the Paulownia tree does not mind calcareous areas.

\section{Data Management}

According to the criteria selected above, all the layers, useful for data processing, have been downloaded from the Lombardy Geoportal [45] as shapefiles, all in the WGS84 UTM Zone $32 \mathrm{~N}$ reference system. Only the rainfall and wind speed layers are not available in the Geoportal and therefore their maps have been developed by collecting the data from the ARPA (Regional Agency for the Environment Protection) Lombardia website [46] and by manipulating them according to the procedure described below.

\subsection{The Rainfall and Wind Maps}

The rainfall amount $(\mathrm{mm})$ and wind speed $(\mathrm{m} / \mathrm{s})$ maps cannot be found in the Geoportal. For this reason, a selection, collection and processing work has been carried out, at last providing two raster maps useful for the final processing: one average rainfall map and one average wind speed map in the Province of Bergamo. The final maps are the result of an average calculation in the decade 2007-2016, for the rainfalls, and only in the year 2016-2017 for the wind speed. The lengthy procedure has already been adopted and described by the author [47]. It is shortly summarized below:

1) selection of a suitable number of ARPA Lombardia [48] meteorological stations (Figure 7) equipped with pluviometers and anemometers well spread in the Province of Bergamo area and the surrounding Lombardy Provinces, with data missing for no more than 30 days in a year;

2) downloading of the corresponding Excel files [49] and calculation of the average rainfall and wind speed quantity for each station and for each year;

3) displaying of the stations and their values in Esri [51] ArcGIS ArcMap 


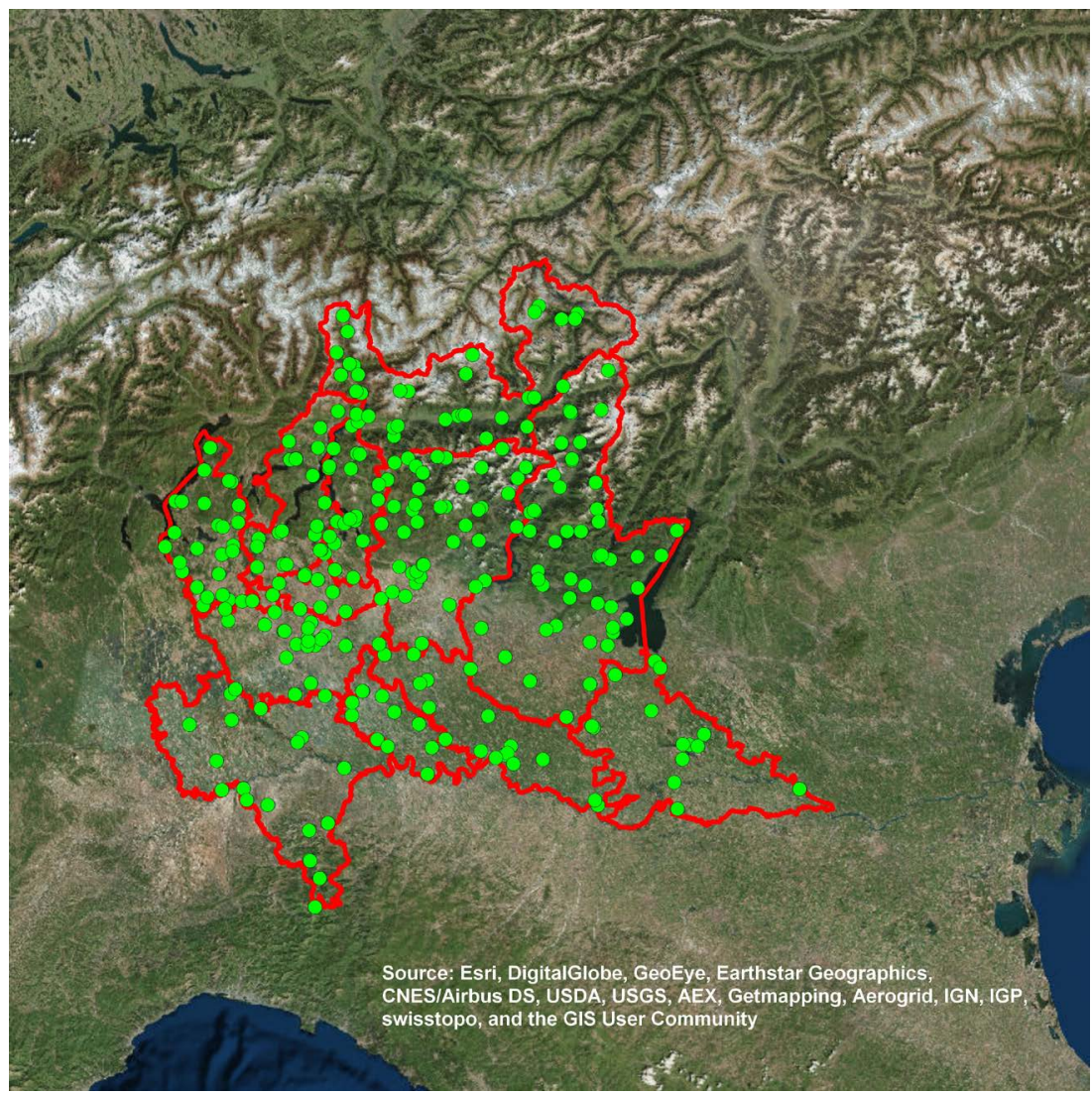

Figure 7. The ARPA Lombardia meteo stations [49] in Lombardy and ArcGIS Imagery Basemap [50].

10.4 and creation of the corresponding shapefiles which have been then interpolated with the IDW technique through the Spatial Analyst Interpolation tool, this way providing one wind speed raster, for the year under examination, and ten rainfall rasters for the selected decade, all at $10 \times 10$ raster resolution and in the WGS84 UTM Zone 32N reference system. The best choice would have been between Splines and IDW, but the literature shows that IDW seems to provide slightly better results than Splines [52]-[57];

4) clipping of these layers, which extend over an area larger than the territory under investigation, with the Province of Bergamo shapefile through the Spatial Analyst Extract by Mask tool, this way providing the final raster wind speed map in the year 2016-2017 (Figure 8) and ten rainfall maps which have been then averaged with the Spatial Analyst Map Algebra tool, allowing to achieve the final rainfall map for the decade 2007-2016 (Figure 9).

Since the wind speed map (Figure 8) shows that the values in the Province of Bergamo do not exceed $4 \mathrm{~m} / \mathrm{s}$, it has been decided to discard this layer in the final analysis, since wind is not an issue in the selected area for the Paulownia growing. As previously said, the young trees do not tolerate wind speed above 28 $\mathrm{km} / \mathrm{h}$, which means about $7.7 \mathrm{~m} / \mathrm{s}$. The result confirms what said previously, i.e. that the Padana Plain is characterized by light wind and high atmospheric stability. 


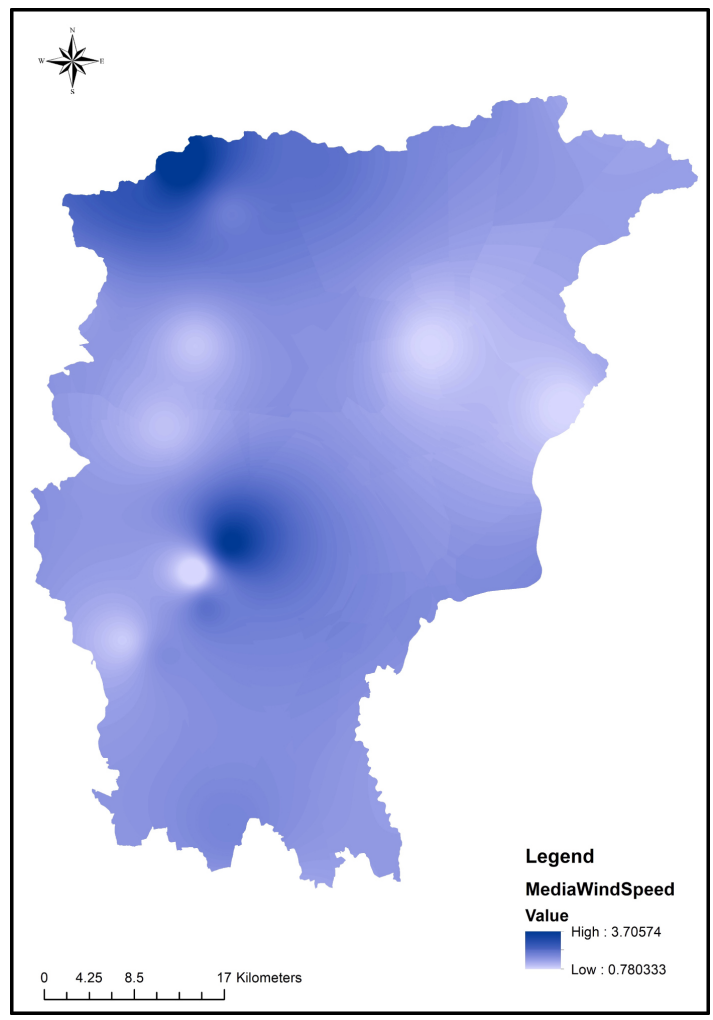

Figure 8. The raster map of average wind speed $(\mathrm{m} / \mathrm{s})$ in the year 2016-2017 in the Province of Bergamo.

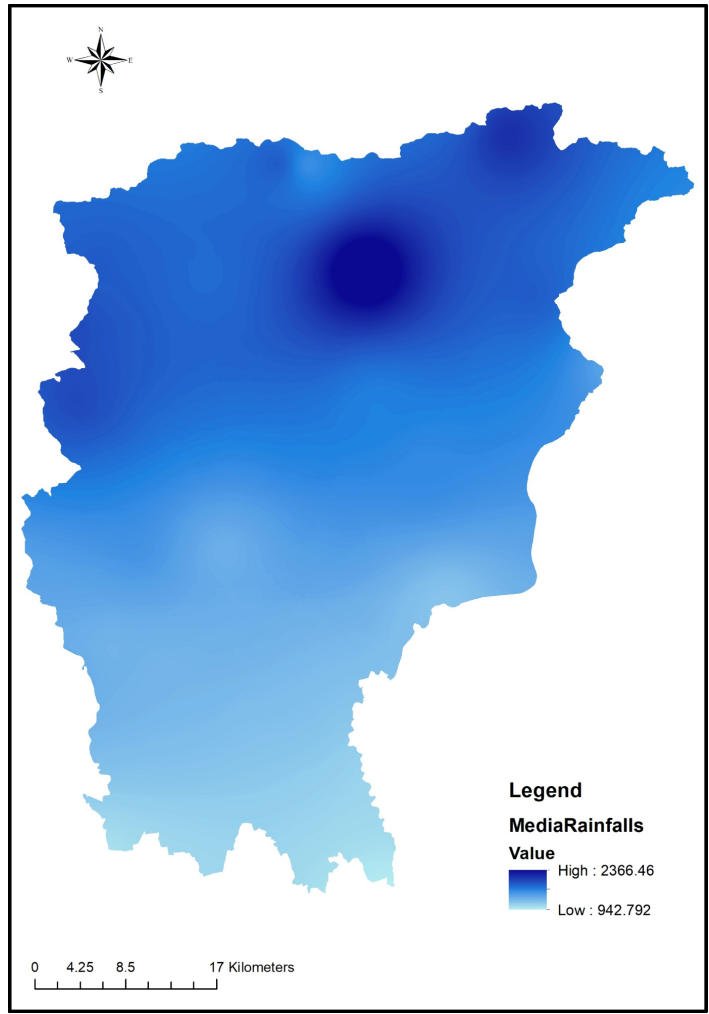

Figure 9. The raster map of average rainfalls $(\mathrm{mm})$ in the decade 2007-2016 in the Province of Bergamo. 
Figure 9 shows that the lower value for average rainfalls in the Province of Bergamo is about $942 \mathrm{~mm}$. Hence it has been decided not to take this layer into account, in the final analysis, since the value exceeds the minimum required of $800 \mathrm{~mm}$ per year for growing Paulownia in the best situation.

\subsection{Shapefiles Geoprocessing}

In this step, the ArcGIS Buffer tool has allowed to create a $50 \mathrm{~m}$ buffer area around the features describing the prone to floods (soaked) terrain in the Province of Bergamo. The selected buffer distance is quite large, but it has been decided to set a more stringent condition and for this reason it has seemed a proper compromise. The other requested shapefiles, describing the soil depth, $\mathrm{PH}$, OC quantity and texture, have been acquired, in ArcMap, by a selection of attributes analysis of the soil map layer of the Province of Bergamo.

\subsection{Raster Layers Selection, Creation and Reclassification}

First of all, all the shapefiles have been converted to raster ones at the same $10 \times$ 10 cell size as the rainfall and wind maps. The Aspect raster has been derived from the DEM one. According to what just said, the final selected layers are listed here: DEM Height, DEM Aspect, Soil texture, Soil PH, Soil OC quantity, Soil depth, Buffer of soaked areas and Land Use, for a total of 8 files. These are all raster layers related to the Province of Bergamo territory in WGS84 UTM Zone $32 \mathrm{~N}$ coordinate system and at the same $10 \times 10$ resolution. At this point, all these files have been reclassified, according to some selected parameters, or range of values, as illustrated in Table 1 and Table 2 . The reclassification has assigned the value 1 to the favourable conditions and the value 0 to the unfavourable ones. A more specific explanation has to be made for the Land Use file; in fact, it has been decided to select, as favourable terrains, the following ones: uncultivated green areas, deteriorated and unkempt areas without vegetation or with stones, areas with brushes, lawns, sparse vegetation areas and grasslands. All the others types of land cover, like the urban, transport, water, cropland, orchard and wood ones have been discarded with the idea that croplands must be kept,

Table 1. The selected reclassification parameters and criteria.

\begin{tabular}{cc}
\hline Layer & Reclassification attribute \\
\hline Buffer of soaked areas & Buffer distance $>50 \mathrm{~m}=1$ \\
Buffer distance $<50 \mathrm{~m}=0$ & PH values from 5.6 to $7.9=1$ \\
Soil PH & Other PH values $=0$ \\
Soil OC quantity & OC quantity $>1 \%=1$ \\
Soil Useful depth & OC quantity $<1 \%=0$ \\
& Useful depth $>1.5 \mathrm{~m}=1$ \\
Soil Map & Useful depth $<1.5 \mathrm{~m}=0$ \\
& Soil texture: loam, sandy loam, silt loam $=1$ \\
Land Use & Other textures $=0$ \\
& Some selected descriptions of land cover $=1$ \\
& Others $=0$
\end{tabular}


Table 2. The selected DEM Height and Aspect reclassification parameters.

\begin{tabular}{cc}
\hline DEM Height $(\mathrm{m})$ & DEM Aspect $^{\circ}$ \\
\hline Height $<800 \mathrm{~m}=1$ & -1 ( Flat areas $)=0$ \\
Height $>800 \mathrm{~m}=0$ & $0-67.5(\mathrm{~N} / \mathrm{NE})=0$ \\
& $67.5-112.5(\mathrm{E})=0$ \\
& $112.5-157.5(\mathrm{SE})=1$ \\
$157.5-202.5(\mathrm{~S})=1$ & $202.5-247.5(\mathrm{SW})=1$ \\
$247.5-292.5(\mathrm{~W})=0$ \\
$292.5-360(\mathrm{NW} / \mathrm{N})=0$
\end{tabular}

the woods already have trees, to be preserved, hydric lands, such as rivers and lakes, are not advised for the Paulownia growing and urban areas do not have many useful places but parks and gardens. This way, for now it has been decided to keep the existing vegetation in woods, parks and gardens, while checking the possibility to replace ill and dead trees and the availability of free plots of land where to plant the Paulownia trees. Also croplands could be examined so as to find some more available terrain.

\section{The Final Analysis and Map}

The final raster processing has been performed with the Spatial Analyst Map Algebra ArcGIS Tool, as explained in Equation (1), and it has allowed to identify the optimal areas for growing the Paulownia tree in the Province of Bergamo.

$$
\text { Paulownia Tree growing }=\prod_{1}^{8} \text { Reclassified Rasters }_{i}
$$

The final raster is function of all the 8 reclassified raster layers (i.e. Reclassified DEM Height, Reclassified DEM Aspect, Reclassified Buffer of Soaked Areas, Reclassified Soil Map, Reclassified Soil PH, Reclassified Soil Depht, Reclassified Soil OC Quantity, Reclassified Land Use) which are multiplied together in the Raster Calculator.

The result of Equation (1) is illustrated in Figure 10 and it shows that 7.5649 $\mathrm{km}^{2}$ of terrain, which means the areas identified by the number 1 in the legend, could be used to grow the Paulownia trees in the most favourable soil and climate conditions in the Province of Bergamo. In fact, the best areas have been returned with a value of 1 , while the not favourable ones with the value 0 . It is important to remember that these are the best fitting areas for the tree growth and they could be made more extensive if taking into account less stringent requirements.

\section{Use of the Identified Best Fitting Areas}

At this point, it has been decided to examine the air quality condition in the Province of Bergamo [58] and the possible use of the Paulownia tree to improve the present situation. 


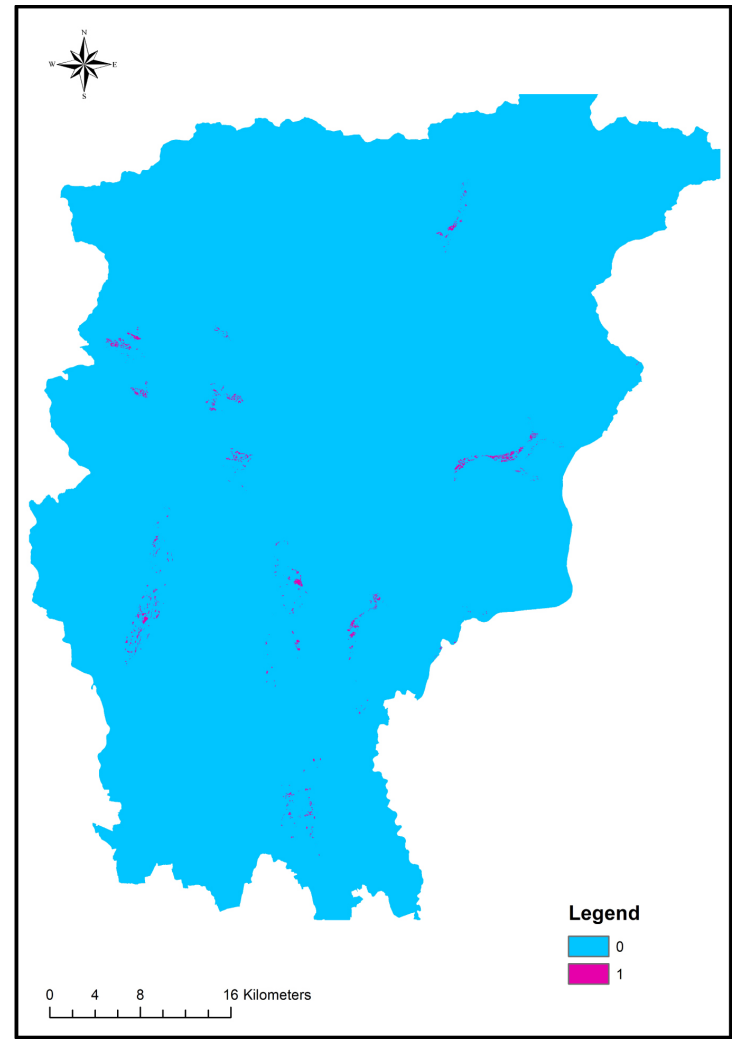

Figure 10 . The product of the 8 reclassified raster layers.

According to the European and Italian low, each region has the power to divide its territory in zones and agglomerations, in which the object and limit values of the air quality must be checked [59]. The classification in zones and agglomerations is provided for by the law D. Lgs. 13 august 2010, n. 155 [60].

According to the law, the Lombardy territory is divided in areas homogeneous for the air quality evaluation [59]:

1) Urban Agglomerations (Agglomeration of Milan, Agglomeration of Bergamo and Agglomeration of Brescia),

2) Zone A: flatlands with high urbanization,

3) Zone B: flatlands,

4) Zone C: rocky chains (Prealps, Apennine and higher mountain),

5) Zone D: valley bottom.

For the $\mathrm{C}$ Zone there is also a further subdivision in $\mathrm{C}_{1}$ (Prealps and Apennine) and $\mathrm{C}_{2}$ (higher mountain), for Ozone $\left(\mathrm{O}_{3}\right)$ evaluation.

Figure 11 shows the last classification (30 November 2011) for the Province of Bergamo territory, where the Agglomeration of Bergamo is indicated by Agg_BG.

By law, it has also been introduced a zone, named Band 1, where special limits must be observed; they refer to vehicles traffic flow and the localization of power supply and waste management plants [59]. For the Province of Bergamo, the Band 1 area matches exactly the Agglomeration of Bergamo and for this reason, from now on, it will be identified as Band 1 .

Figure 12 illustrates the Band 1area in the Province of Bergamo which, of 


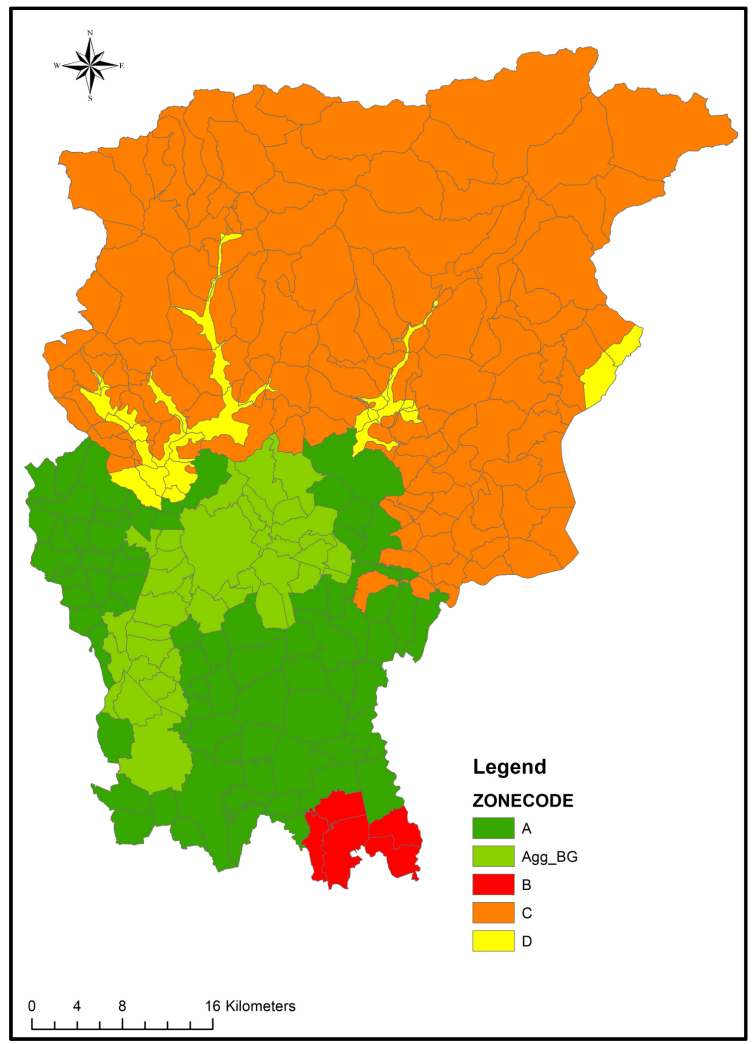

Figure 11. Classification of the homogeneous air quality areas in the Province of Bergamo.

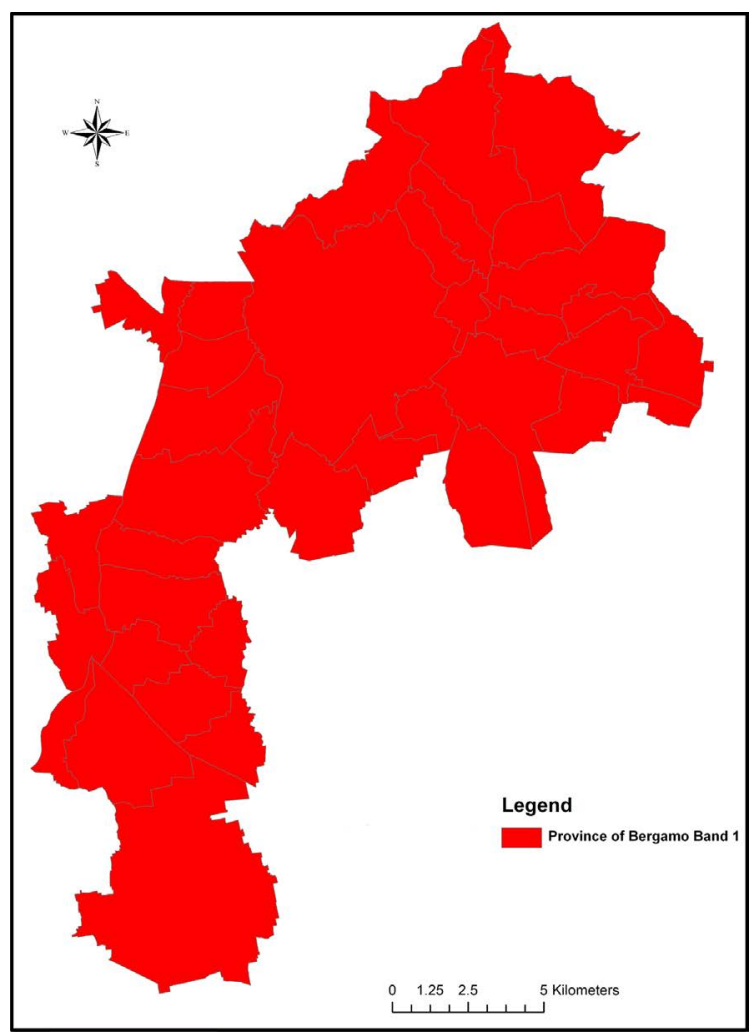

Figure 12. The Band 1 area in the Province of Bergamo. 
course, is equal to the Agglomeration of Bergamo.

It has then been decided to concentrate only on the commons in the Province of Bergamo belonging to the so called Band 1 and to analyse the pollutants PM10 and PM2.5 levels.

Particulate matter (PM) [61] is microscopic solid or liquid matter suspended in Earth's atmosphere. It is indicated with $\mathrm{PM} x$, where $x$ identifies the size of the particles in $\mu \mathrm{m}$.

Heating, traffic, agriculture, etc. are the main sources of particulate pollutants.

They are classified as highly dangerous for human and animal health and they are the cause of the rising number of pulmonary and cardio circulatory diseases, as well as of cancer.

In April 2008, Europe has adopted new law measures (2008/50/EC) which include the limits of the air quality and pollutants These recommendations, in Italy, are represented by the 13 August 2010, n.155 law. These law values and limits [62] [63] for men health are described in Table 3.

On the other side, industrialization, the changing in land use destination (such as deforestation) and human impact are the causes of the fast accumulation of $\mathrm{CO}_{2}$ in the air, which in turn leads to global warming, the melting of polar ice, oceans acidification, diseases, etc. (Figure 13) [64] [65].

It is known that Carbon Dioxide is also the cause of the presence of particulate pollutants in the air, due to fossil fuel [65]. The burning of fossil fuels, particularly diesel, wood stoves and cooking with wood, emits $\mathrm{CO}_{2}$ and it also releases air pollution aerosols (tiny particles suspended in the air/lower atmosphere). Black carbon (soot) has a surface warming effect, second only to $\mathrm{CO}_{2}$. The largest source is from burning forests [64]. From the middle of the 19th century up till now, the level of $\mathrm{CO}_{2}$ has grown with more than $25 \%$. Before that, such levels have not been reached for 1.6 million years (Figure14) [66].

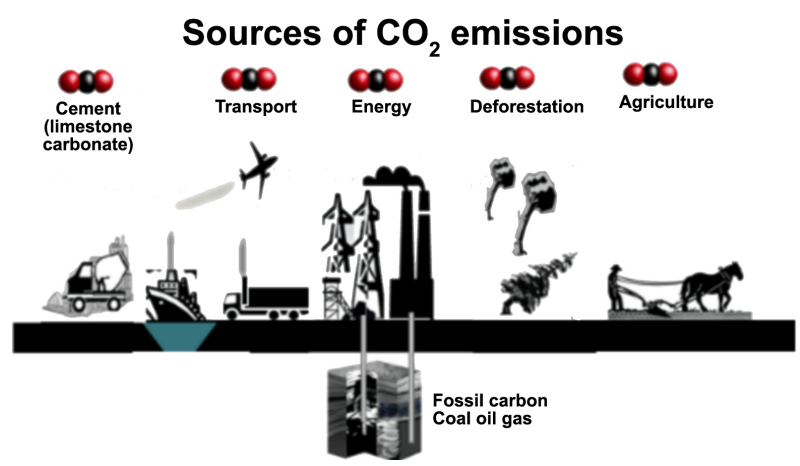

Figure 13. Sources of $\mathrm{CO}_{2}$ emissions [64].

Table 3. The law limits for particulate matter PM10 and PM2.5 [61].

\begin{tabular}{ccc}
\hline Air Pollutant & Daily Limit & Yearly Limit \\
\hline PM10 & $50 \mu \mathrm{g} / \mathrm{m}^{3}$ for no more than & $40 \mu \mathrm{g} / \mathrm{m}^{3}$ \\
PM2.5 & 35 days a year & $25 \mu \mathrm{g} / \mathrm{m}^{3}($ since 2015) \\
\hline
\end{tabular}




\section{Growth of $\mathrm{CO}_{2}$ emissions \& concentrations in atmosphere}

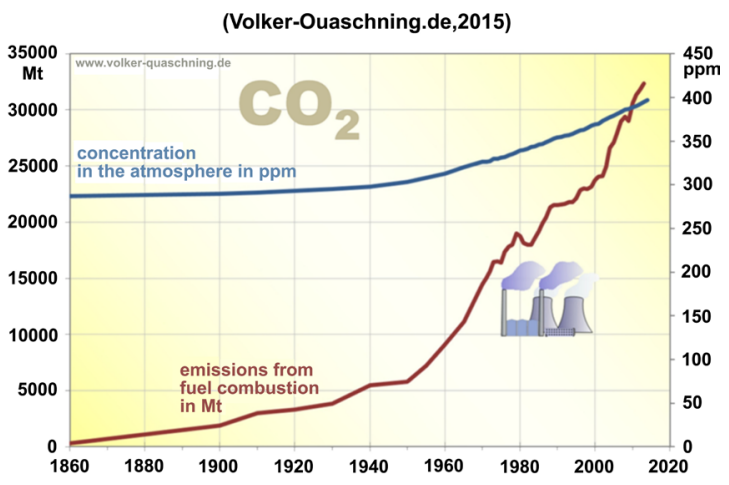

Figure 14. The increase of $\mathrm{CO}_{2}$ emissions in time [67] [68].

The choice to concentrate here only on Particulate Matter $\mathrm{PMx}$ and $\mathrm{CO}_{2}$ is due to the fact that the Paulownia tree, as said before, can contribute to lower their dangerous levels in the atmosphere, with the aid of its big leaves.

ARPA Lombardia has more than 150 stations [69] recording the concentrations of the main air pollutants, among which, PM10 and PM2.5. These data are published daily on the ARPA website.

For this project, the PM10 and PM2.5 data have been downloaded for each common, in the Province of Bergamo, belonging to the so called Band 1 (for a total of 37), previously described, in the year 2017 [70].

By law, as said before, the annual limit values for PM10 is $40 \mu \mathrm{g} / \mathrm{m}^{3}$ and 25 $\mu \mathrm{g} / \mathrm{m}^{3}$ for PM2.5, while the daily limit of $50 \mu \mathrm{g} / \mathrm{m}^{3}$ shouldn't be exceeded for more than 35 days a year only for PM10 [71].

The data have been downloaded from the ARPA Lombardia website: excel files, with daily values of Particulate matter (both PM10 and PM2.5) for the Band 1 commons, which are 37 in the Province of Bergamo, in the year 2016-2017.

Their yearly average has been calculated and then edited, in ArcMap, in the attribute table of the shapefile of the 37 commons, adding one column for PM10 and another for PM2.5 values. Also another column has been created, which lists the number of days, for each common, when PM10 values have exceeded the daily limit of $50 \mu \mathrm{g} / \mathrm{m}^{3}$.

Figure 15 shows that the higher average PM10 value, in the Band 1 commons, is about $36.43 \mu \mathrm{g} / \mathrm{m}^{3}$, which is under the annual law limit of $40 \mu \mathrm{g} / \mathrm{m}^{3}$, while, for PM2.5, Figure16 shows that the annual limit of $25 \mu \mathrm{g} / \mathrm{m}^{3}$ is exceeded in even 27 commons, while in 3 it is in the range $23-25 \mu \mathrm{g} / \mathrm{m}^{3}$ and in 7 in the range $21-23$ $\mu \mathrm{g} / \mathrm{m}^{3}$.

Even if the results for PM10 seem to be encouraging, it has been decided to take into account the number of days in a year in which the daily limit of 50 $\mu \mathrm{g} / \mathrm{m}^{3}$ is exceeded, for each common, which should be under 35 . It is possible to see that only one common respects this limit, while in all the other 36 the number of recommended days is exceeded. 


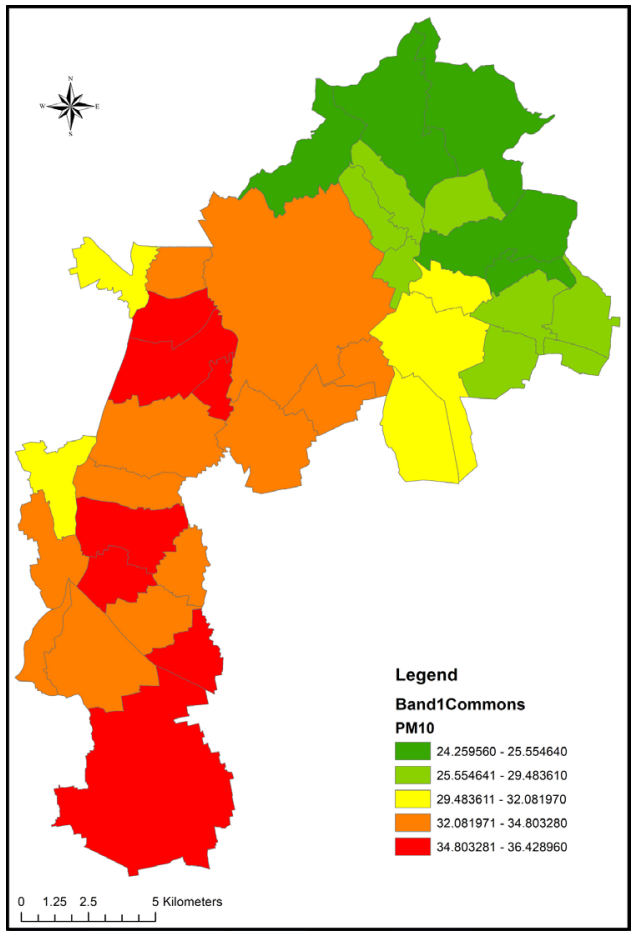

Figure 15. The year average PM10 values in the Band 1 commons of the Province of Bergamo.

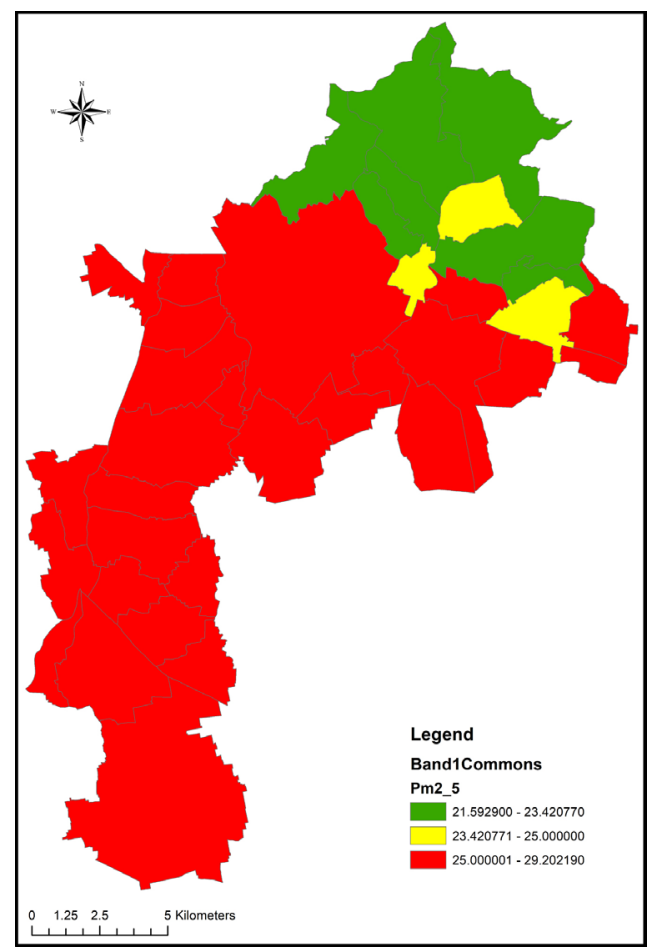

Figure 16. The year average PM2.5 values in the Band 1 commons of the Province of Bergamo.

Figure 17 shows that the situation is not good at all also for PM10 and that particulate pollutants are an important issue for the Province of Bergamo, since 


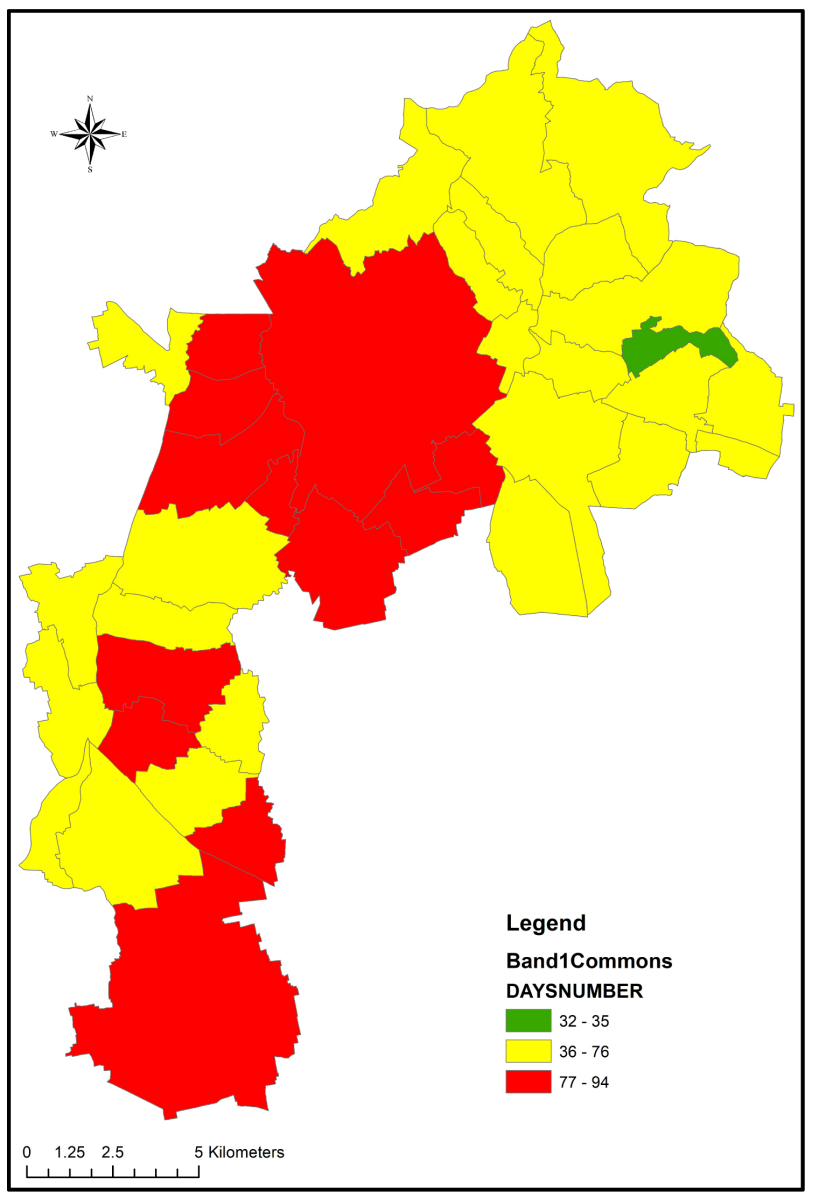

Figure 17. Number of days of PM10 values over the limit in the Band 1 commons of the Province of Bergamo.

they are the cause of many diseases for all the people who breathe this polluted air.

No specific analysis has been carried out for Carbon Dioxide $\left(\mathrm{CO}_{2}\right)$ levels in the Province of Bergamo, but of course $\mathrm{CO}_{2}$ emissions need to be taken into account by default, since they are an extremely important world issue and the main cause of air pollution concerns for our planet.

Starting from the results just achieved, it has been decided to look at the disposition of the best fitting areas, previously found, in respect to the Band 1 zone.

For this reason, the final raster layer has been converted, in ArcMap, to a polygon one with only the areas with value equal to 1 , which means only the best fitting ones. This layer has then been displayed together with the Band 1 shapefile of the commons in the Province of Bergamo. Since these commons can be enclosed in a square box with the side of about $33 \mathrm{~km}$, it has been set a distance equal to its $10 \%$, i.e. $3 \mathrm{~km}$. Then, through a selection by location tool, the best fitting areas, within this distance, in respect to the Band 1 shapefile, have been selected (in cyan in Figure 18). They cover an area of $3 \mathrm{~km}^{2}$ and they could be considered as a priority to create a green lung close to the more polluted zone, i.e. the Band 1, in the Province of Bergamo. 


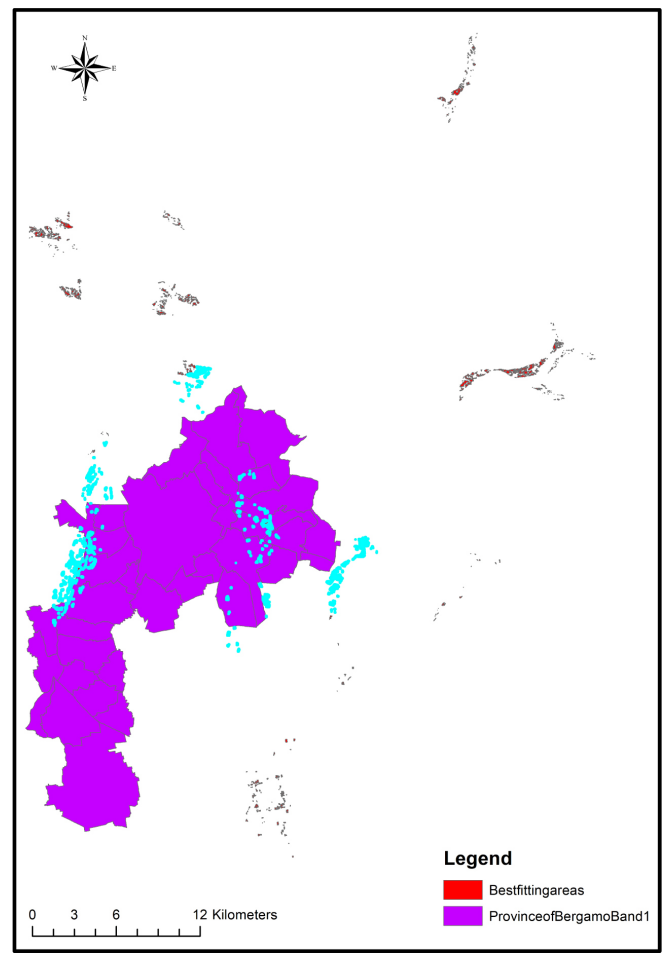

Figure 18. The selected best fitting areas close to the Band 1 commons of the Province of Bergamo.

As previously said, each acre of trees can absorb 13 tons of harmful $\mathrm{CO}_{2}$ gases and particles from the air each year [23]. Since $1 \mathrm{~km}^{2}$ is equal to 247.105 acres, the identified area is of 741.315 acres, this way allowing to absorb 9637 tons of $\mathrm{CO}_{2}$ and particles in a year; since each tree can release about $13 \mathrm{lbs}$ of oxygen per day [23], the oxygen amount in the air would be highly increased.

Deciding to take into account, as second step, also the commons of the A Zone, which means the flatlands with high urbanization, performing the same procedure just described, other best fitting areas have been selected (Figure 19). In this case, the distance set to perform the selection by location tool is of $4 \mathrm{~km}$, since the A Zone polygon can be enclosed in a wider box with a side of about 40 $\mathrm{km}$ and its $10 \%$ corresponds to $4 \mathrm{~km}$. Then, taking into account the previously identified areas for the Band 1 zone, it has been possible to identify others (in cyan in Figure 19), which cover an extension of $0.87 \mathrm{~km}^{2}$.

The employment of these new areas could obviously contribute to improve the quality of the air in the Province of Bergamo, in fact they could absorb, according to the numerical passages just described for the Band 1 commons, about 2795 tons of $\mathrm{CO}_{2}$ and particles in a year and release very high quantities of $\mathrm{O}_{2}$ per day.

Of course there are some best fitting areas left, of about $3.69 \mathrm{~km}^{2}$, which are outside the Band 1 and A Zone, and they belong to the less polluted zones in the Province of Bergamo; they could be considered as a contribution against pollution, in a final step, after fulfilling the first and more necessary two steps just described before. 


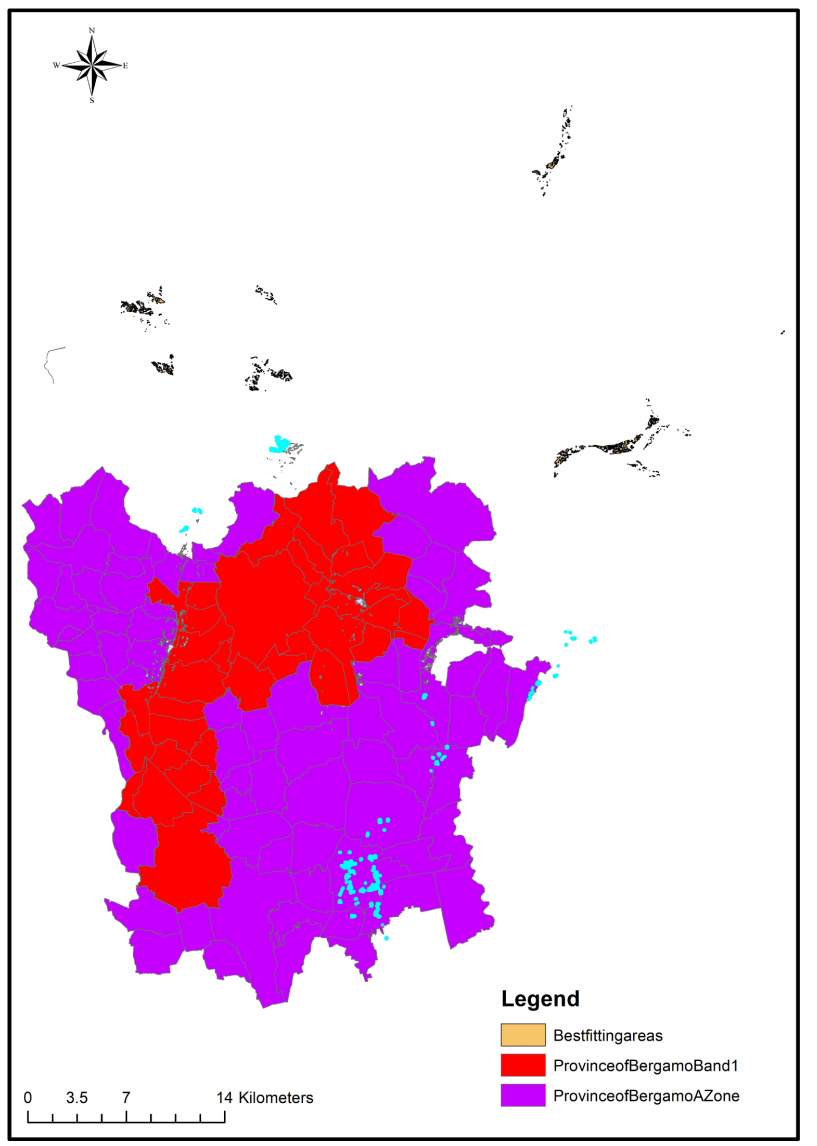

Figure 19. The selected best fitting areas close to the A Zone commons of the Province of Bergamo.

\section{Conclusion}

According to the idea of finding the best areas for growing the Paulownia tree in the Province of Bergamo, a specific GIS analysis has been carried out to select the most favorable soil and climate conditions. The achieved results show that $7.5649 \mathrm{~km}^{2}$ of terrain could be harvested with these trees whose big leaves have the capability to absorb great quantities of $\mathrm{CO}_{2}$ and particles and release large amounts of Oxygen in the air; in fact, as previously said, each acre of trees can absorb 13 tons of harmful $\mathrm{CO}_{2}$ gases and particles from the air each year and each tree can release about 13 lbs of oxygen per day [23]. These best fitting areas could be considered as an opportunity to test the green solution suggested here to fight air pollution. Of course, the analysis has been carried out for a specific territory, i.e. the Province of Bergamo, but it could be adjusted for any other place by defining different climate and soil conditions. This is a first step, because now this information must be spread to the citizens and municipalities of the more polluted commons and decisions must be taken to accomplish what is suggested in this paper. By now, it is a hope that a practical action is going to be started as soon as possible, but we are positive and trust the people to make the right choice and ask for better environmental conditions for now and for the future. 


\section{Final Remarks and Future Development}

The previous analysis has allowed to identify the best fitting areas for growing the Paulownia tree in the Province of Bergamo.

They are not wide, but, as it has been said before, less stringent conditions could be taken into account and also other different land use areas could be investigated and evaluated as possible candidates, such as park and gardens in the urban areas, where it could be advised to plant these trees on available terrain. This could really become a useful approach which would directly contribute to absorb pollutants, provide shade and lower temperature in the cities, where traffic and urbanization reach high levels, while displaying their beautiful purple flowers and big green leaves.

Also the enlargement of the soil PH range, selected here, could be considered.

The results, achieved with the analysis just performed, also show that the best places are well distributed in the zones where air is more polluted, which means the A Zone and also Band 1, where there are more rigid law limitations against pollution [59].

Anyway, this is a good start and represents a new contribution against air pollution.

Some other interesting properties of the Paulownia trees could also be considered, such as their capability to consolidate terrains with erosion and therefore areas prone to landslides, as well areas prone to hydrogeological risk. In this case, it would be good to raise the altitude limit, considered here, and to take it up to $2000 \mathrm{~m}$, where the Paulownia trees can still adapt and live, and also resize the buffer area of $50 \mathrm{~m}$, previously selected around the soaked areas, to a smaller one.

\section{Acknowledgements}

Thanks for his original idea are due to the GIS course student, at the University of Bergamo (Engineering), Giuseppe Traettino who is going to develop the subject, here described, in his degree thesis, and also to Professor Maria Sole Brioschi for her kind and useful advice.

\section{References}

[1] http://climaterussia.org/clean-tech/paulownia-an-alien-with-the-green-mission

[2] https://ei-fund.ru/

[3] https://en.wikipedia.org/wiki/Paulownia_tomentosa

[4] https://naturewalk.yale.edu/trees/paulowniaceae/paulownia-tomentosa/empress-72

[5] http://www.jstor.org/pss/2439100

[6] http://www.dragontrees.com/dragonhi.html

[7] http://www.ideassonline.org/public/pdf/PaulowniaChina-ENG.pdf

[8] http://paulownia.bg/en/paulownia-features

[9] https://www.cabi.org/isc/datasheet/39100

[10] https://www.fast-growing-trees.com/blog/royal-empress-trees-invasive-heres/ 
[11] http://www.paulownia-it.com/it/

[12] http://www.paulowniasocialproject.it/

[13] http://www.futuregreensrl.com/?page_id=95

[14] https://www.progettoitalianews.net/news/investire-e-guadagnare-nel-legno-con-lapaulownia/

[15] http://www.cathaia.com/it/

[16] https://www.facebook.com/asociatiepaulownia/?hc_ref=ARTHPRKjpFOXtOCOlIg4 Vpw-mWmlSj7YK0VetTLMUZINFg_V0NjQ4frxniuo-WcHwK0

[17] https://www.nytimes.com/2000/12/23/your-money/besides-money-a-gentleman-tre e-farmer-must-have-lots-of-patience.html

[18] http://www.worldpaulownia.com/carter-center-auction/

[19] http://www.tandfonline.com/doi/abs/10.1080/14728028.2014.952353

[20] http://woodturnersunlimited.com/index.php/wood/hardwoods/104-paulownia-tom entosa-a-true-mystery-wood

[21] http://paulowniatrees.eu/learn-more/paulownia-environment/

[22] http://paulowniadevelopment.ro/en/paulownia-plantation/

[23] http://www.dragontrees.com/dragonbe.html

[24] https://en.wikipedia.org/wiki/Melliferous_flower

[25] http://www.ibimet.cnr.it/homepage\#null

[26] http://fioriefoglie.tgcom24.it/2009/11/la-classifica-degli-alberi-anti-smog/

[27] http://paulowniatrees.eu/products/requirements-for-growing-paulownia/

[28] http://www.paulownia-it.com/it/coltivare/

[29] http://www.paulownia.es/english/growing-conditions/

[30] https://en.wikipedia.org/wiki/Soil_carbon

[31] http://www.arpa.veneto.it/arpavinforma/indicatori-ambientali/indicatori_ambiental i/geosfera/qualita-dei-suoli/contenuto-di-carbonio-organico-nello-strato-superficial e-di-suolo/view

[32] http://docplayer.it/35956-L-aria-che-respiro-l-inquinamento-atmosferico-locale-e-g lobale-dal-cittadino-alle-istituzioni-insieme-per-migliorare-la-qualita-dell-aria.html

[33] http://metro.co.uk/2017/06/27/china-planning-forest-city-with-one-million-plantsand-40000-trees-6738726/

[34] https://www.forbes.com/sites/trevornace/2017/06/30/chinas-new-forest-city-will-m ake-you-rethink-urban-cities/\#21dd68a9dabd

[35] https://www.stefanoboeriarchitetti.net/stefano-boeri-biografia/

[36] https://www.stefanoboeriarchitetti.net/project/liuzhou-masterplan-2/

[37] https://www.indy100.com/article/forest-city-china-air-pollution-town-trees-liuzhou -stefano-boeri-climate-change-paris-agreement-7809736

[38] http://www.provincia.bergamo.it/Provpor/portalProcess.jsp

[39] http://www.italyheritage.com/genealogy/surnames/regions/lombardia/

[40] https://it.wikipedia.org/wiki/File:Province_of_Bergamo_SRTM.png

[41] https://www.ecodibergamo.it/stories/bergamo-citta/bergamo-citta-sempre-piu-verd ema-122-alberi-verranno-abbattuti_1238334_11/

[42] http://www.bergamo.coldiretti.it/verde-urbano-bergamo-e-maglia-rosa-in-lombard ia-per-1-aumento-della-superficie-pro-capite.aspx?KeyPub=GP_CD_BERGAMO_P 
ROV\%7CPAGINA_CD_BERGAMO_ANP\&Cod_Oggetto=100273071\&subskintype $=$ Detail

[43] http://www.ersaf.lombardia.it/servizi/notizie/notizie_homepage.aspx

[44] http://www.ersaf.lombardia.it/upload/ersaf/gestionedocumentale/Salinita_ERSAF_g en_784_9093.pdf

[45] http://www.geoportale.regione.lombardia.it/

[46] http://www.arpalombardia.it/Pages/Scopri-Arpa-Lombardia.aspx

[47] Marana, B. (2017) A Simplified ArcGIS Approach for Landslides Risk Assessment in the Province of Bergamo. Journal of Geographic Information System, 9, 699-716. https://doi.org/10.4236/jgis.2017.96044

[48] http://www.arpalombardia.it/siti/arpalombardia/meteo/osservazioniedati/datitemp oreale/rilevazioni-in-tempo-reale/Pagine/Rilevazioni-in-tempo-reale.aspx

[49] http://www.arpalombardia.it/siti/arpalombardia/meteo/richiesta-dati-misurati/Pagi ne/RichiestaDatiMisurati.aspx

[50] https://www.arcgis.com/home/gallery.html

[51] www.esri.com

[52] Noori, M.J., Hassan, H.H. and Mustafa, Y.T. (2014) Spatial Estimation of Rainfall Distribution and Its Classification in Duhok Governorate Using GIS. Journal of Water Resource and Protection, 6, 75-82. https://doi.org/10.4236/jwarp.2014.62012

[53] Chen, F.-W. and Liu, C.-W. (2012) Estimation of the Spatial Rainfall Distribution Using Inverse Distance Weighting (IDW) in the Middle of Taiwan. Paddy and Water Environment, 10, 209-222. https://doi.org/10.1007/s10333-012-0319-1

[54] Yang, X.H., Xie, X.J., Liu, D.L., Ji, F. and Wang, L. (2015) Spatial Interpolation of Daily Rainfall Data for Local Climate Impact Assessment over Greater Sydney Region. Advances in Meteorology, 2015, Article ID: 563629.

[55] Basistha, A., Arya, D.S. and Goel, N.K. (2008) Spatial Distribution of Rainfall in Indian Himalayas-A Case Study of Uttarakhand Region. Water Resources Management, 22, 1325-1346. https://doi.org/10.1007/s11269-007-9228-2

[56] Dirks, K.N., Hay, J.E., Stow, C.D. and Harris, D. (1998) High-Resolution Studies of Rainfall on Norfolk Island: Part II: Interpolation of Rainfall Data. Journal of Hydrology, 208, 187-193. https://doi.org/10.1016/S0022-1694(98)00155-3

[57] http://www.ajournal.co.uk/pdfs/BSvolume7(2)/BSVol.7\%20(2)\%20Article\%206.pdf

[58] http://www.arpalombardia.it/qariafiles/RelazioniAnnuali/RQA_BG_2016.pdf

[59] http://www.regione.lombardia.it/wps/portal/istituzionale/HP/DettaglioRedazionale/ ser-

vizi-e-informazioni/Enti-e-Operatori/ambiente-ed-energia/Inquinamento-atmosfer ico/zonizzazione-territorio-regionale/zonizzazione-territorio-regionale

[60] http://www.normattiva.it/uri-res/N2Ls?urn:nir:stato:decreto.legislativo:2010-08-13; 155

[61] https://en.wikipedia.org/wiki/Particulates

[62] https://www.pm10.it/limiti.html

[63] https://www.pm10.it/dlgs155-2010.html

[64] http://www.onlyzerocarbon.org/sources_co2.html

[65] https://static.secure.website/wscfus/299177/3002429/break-tox-health.png

[66] http://www.onlyzerocarbon.org/co2_levels.html 
[67] http://www.onlyzerocarbon.org/co2_emissions.html

[68] https://www.volker-quaschning.de/datserv/CO2/index_e.php

[69] http://www.arpalombardia.it/sites/qaria/_layouts/15/qaria/ReteDiRilevamento.aspx

[70] http://www.arpalombardia.it/sites/qaria/_layouts/15/qaria/RicercaIDati2.aspx

[71] http://www.arpalombardia.it/sites/qaria/_layouts/15/qaria/Inquinanti.aspx\# 